\title{
Review
}

\section{Professional ethics in complementary and alternative medicines in management of Parkinson's disease}

\author{
Hee Jin Kim ${ }^{\mathrm{a}, \mathrm{b}}$, Beomseok Jeon ${ }^{\mathrm{b}, \mathrm{c}, *}$ and Sun Ju Chung ${ }^{\mathrm{d}}$ \\ ${ }^{a}$ Department of Neurology, Konkuk University Medical Center, Konkuk University School of Medicine, Seoul, \\ South Korea \\ ${ }^{\mathrm{b}}$ Parkinson Disease Study Group, Seoul National University Hospital, Seoul, South Korea \\ ${ }^{\mathrm{c}}$ Department of Neurology and Movement Disorder Center, College of Medicine, Seoul National University, \\ Seoul, South Korea \\ ${ }^{\mathrm{d}}$ Department of Neurology, Asan Medical Center, University of Ulsan College of Medicine, Seoul, South Korea
}

Accepted 5 August 2016

\begin{abstract}
The practice of complementary and alternative medicine (CAM) is not, at present, considered an integral part of conventional medicine. As the popularity of CAM grows and access to information about CAM increases through the media and internet where CAMs are often promoted, patients are at risk of exposure unvalidated information. Therefore, there is a need for physicians to examine objectively the efficacy and safety of CAM, compare it with current medications, and become actively involved in the CAM treatment with patients. In accordance with these needs, this manuscript reviews the utility, scientific evidence, safety and cost-effectiveness of CAM in the treatment of Parkinson's disease (PD). We also address the ethical issues of CAM practices.
\end{abstract}

Keywords: Parkinson's disease, complementary and alternative medicines, complementary medicines, traditional medicine, acupuncture, herbal medicine, review

\section{INTRODUCTION}

Since Parkinson's disease (PD) is a progressive neurodegenerative disease, patients continue to experience a decline in function and capacity for daily activities despite optimal medical or surgical management [1]. It is, therefore, understandable that patients often seek other resources such as complementary and alternative medicine (CAM), hoping that such treatments might bring symptomatic relief or stop the progression of diseases they have been told modern medicine cannot cure.

\footnotetext{
${ }^{*}$ Correspondence to: Beomseok Jeon, M.D., Ph.D., Department of Neurology, College of Medicine, Seoul National University, 28 Yongon-dong, Chongno-gu, Seoul 110-744, Korea. Tel.: +822 2072 2876; Fax: +82 2744 1785; E-mail: brain@snu.ac.kr.
}

However, many experts and critics have raised concerns that the popularity of CAM is growing without scientific support or evidence for efficacy, as discussed by Ernst [2]. He pointed out that the ethical principles which apply to medicine in general should apply to CAM, but at this stage CAM is largely unregulated. He was particularly concerned about the use of ineffective procedures, publication of false health claims, misuse of the title 'Doctor' by non-medically trained clinicians, the failure to obtain informed consent, the failure to monitor and report adverse effects, the nondisclosure of conflicts of interest, and the fabrication of research data [2]. In spite of all these concerns, patients with chronic nervous system diseases, including PD, are willing to receive experimental treatments, even at the risk 
of experiencing adverse events [3, 4], as evidenced in our Korean nationwide survey of PD patients and caregivers. In our survey of patient knowledge and attitudes towards experimental treatments, more than $50 \%$ of patients responded they did not possess correct information regarding safety and efficacy of stem cell transplantation or bee venom acupuncture [3]. More disturbing was the finding that $55.3 \%$ and $42 \%$ of patients with PD answered that they were interested in receiving stem cell transplantation or bee venom acupuncture respectively, despite a lack of evidence of the safety and efficacy of these experimental treatments [3]. Because of a desperate desire for a cure, patients choose CAM based on limited information from uncertain sources rather than scientific evidence despite the possibility of being ineffective or even harmful, and a waste of time and cost. Information sources for CAM are rarely objective and in the case of PD mainly from friends [5, 6], a relative or a neighbor [5-7], or patients themselves [8]. Only $11-20 \%$ of patients who used CAM received their referral from a healthcare professional or an oriental medicine physician [5-8].

Another disturbing point about CAM usage is that patients are reluctant to inform their treating physicians, who may be unaware of what medications are being taken and therefore cannot provide help for the actual conditions [9]. Among PD CAM users, 16\% and $57.1 \%$ informed their physicians of their use of CAM in Singapore and Argentina, respectively $[6,7]$. More than half did not consult their treating physician before starting CAM in USA [5]. Patients usually do not inform their physicians about CAM because they assume the physician does not need to know, or they presuppose a negative reaction from the physician [10]. There is, therefore, a risk of harm as they are not properly advised by informed medical professionals.

Hence, there is a need for physicians to assess objectively the efficacy and safety of CAM scientifically, compare it with the evidence for current medications, and become actively involved in the CAM treatment with patients. In accordance with these needs, we review the utility, scientific evidence, safety and cost-effectiveness of CAM in PD and address the ethics of CAM practices.

\section{DEFINITION OF CAM}

The National Center for Complementary and Alternative Medicine (NCCAM) defines CAM practices as those not, at present, considered an integral part of conventional medicine [11]. The words "complementary" generally refers to using a nonmainstream approach together with conventional medicine, while the word "alternative" refers to a non-mainstream approach in place of conventional medicine [12]. The NCCAM has grouped complementary treatments into three main domains: 1) Natural products including a variety of products such as herbs, vitamins, and minerals, and probiotics; 2) mind and body practices including a large and diverse group of procedures or techniques administered or taught by a trained practitioner or teacher - for example, acupuncture, massage, meditation, movement therapies, relaxation techniques, spinal manipulation such as chiropractic and osteopathic manipulations, tai chi, qi gong, yoga, healing touch, and hypnotherapy; 3) other complementary health approaches which may not neatly fit into either natural products or mind and body practices - for example, the practices of traditional healers, Ayurvedic medicine, traditional Chinese medicine, homeopathy, and naturopathy [12].

\section{EPIDEMIOLOGY OF CAM}

CAM use is common among PD patients across the globe. In Asia, frequency of CAM use is $61 \%$ and $76 \%$ in Singapore and in Korea, respectively [6, 8]. However, it is also high in western countries ranging from 34 to $54 \%[5,7,13,14]$. Although a diverse spectrum of CAM is used for PD, acupuncture is the intervention most often used worldwide [15]. Other commonly used CAMs included massage, herbs, and vitamins/health supplements. Cultural background appears closely related to selection of CAM type [15]. Natural products such as vitamins and herbs were the most commonly used CAM for PD in the US [5], while mind and body practices such as acupuncture, yoga, and massage were common in Sweden [13], Argentina [7], and the UK [14]. In Asian countries, traditional or oriental medicine was the most common CAM $[6,8]$.

Although the main reason for trying CAM in patients with PD was to improve PD symptoms, a number of patients chose CAMs for other reasons such as "own belief in the treatment" [13], "use as a tonic" [14], and even for no specific reasons [8]. Other reasons included enhancement of the effects of prescription medications [6], and the management of non-motor symptoms, such as fatigue [8], pain [8, 14], and constipation [8]. 
Socio-demographic factors correlated with CAM use were higher income [5], rural location [8], perceived poor health [13], female gender [7], and younger age [14]. Some studies showed CAM users had a higher educational level than CAM non-users $[5,13]$. Kim, et al. found that patients with lower educational level tended to favor traditional oriental medicine and those with a higher educational level tended to favor traditional food and massage therapies, suggesting that specific modalities of CAM may vary depending on educational background [8]. Certain disease-specific factors, such as younger age at onset of PD [5, 14], higher levodopa dose [8], severity of symptoms [6], and longer duration of PD [8] were related to CAM use. However, none of the sociodemographic factors or disease-specific factors have been consistently associated with the use of CAMs in other studies.

\section{SELF-REPORTED EFFICACY OF CAM}

Three studies evaluated self-reported efficacy using a structured or semi-structured questionnaire exploring the usage of CAM $[6,8,13]$. Response rates varied from $81 \%$ to $100 \%$ [6, 8, 13]. Forty percent of CAM users in Singapore subjectively reported some degree of improvement, $58 \%$ reported no improvement and $2 \%$ reported a worsening of their parkinsonian symptoms [6]. Although 41.6\% (37/89) of CAM users in Korea reported an improvement in their PD symptoms, the majority (83.8\%) reported only a mild beneficial effect and 9.6\% (9/94) experienced adverse effects from CAM. Nonetheless, $57.4 \%$ of CAM users answered that they planned to continue using CAM [8]. In Sweden, self-reported efficacy differed depending on type of CAM [13]. For acupuncture, 50\% found no improvement while 50\% reported some improvement. For herbal medicines and other drugs, one third reported good improvement, one third some improvement and the remaining third no effect. However, the majority reported no effect for other CAM alternatives [13].

\section{SCIENTIFIC EVIDENCE REGARDING EFFECTIVENESS OF ACUPUNCTURE FOR PD}

\section{Experimental studies}

During the last decade, several experimental studies suggested that acupuncture may have neuroprotective effects [16-30] as well as symptomatic benefits [19, 24-29, 31-39] in PD animal models. The suggested neuroprotective mechanisms include reduction of oxidative stress [30, 33, 37], up-regulation of neurotrophic factors [17, 35, 39], modulation of neuronal activity in basal ganglia circuits [31, 32, 35], attenuation of microglial activation $[18,21,23]$, and modulation of apoptosis [22, 29, 33], and neuroinflammation [18, 21, 23, 33]. However, the precise mechanisms of the putative neuroprotective and therapeutic effects of acupuncture are still unclear. There are no studies evaluating the longlasting effect of acupuncture following cessation of treatment. Thus, whether the neuroprotective effect of acupuncture is transient is not known.

In acupuncture, disease is explained by an imbalance in the flow of life energy "Qi" through the meridian system, which is accessible at various points. Thus stimulating acupoints is believed to restore body homeostasis. If some points are considered more therapeutically valuable than others, selection of acupoints may be critical. Nevertheless, there was no consensus of animal acupoints among the experimental studies reviewed. The acupoints used in Korean and China were far different [16-22, 24, 26, 28-32, 34, 35, 37, 38, 40]. Moreover, selection of acupoints differed depending on study groups within China. To demonstrate the distinctive and beneficial effects of a specific acupoint, nonacupoint acupuncture as well as placebo acupuncture is needed as a control intervention group. However, nonacupoint acupuncture has not been applied in the majority of reported studies $[17,18,22,26-32,35$, $38,40]$.

The parameters and treatment regimens of acupuncture are said to be related to its therapeutic effect. However, needle type, depth of insertion, and needle retention time were not consistent across trials. Frequency, duration, and number of treatment sessions were also highly variable. Several studies did not even report some of those parameters. There were also regional differences in the selection of acupuncture type. Electroacupuncture was preferred over needle acupuncture in China [17-19, 30-32, 35, $36,38,39]$, while needle acupuncture [20, 21, 24-26, $29,34,40]$ and venom acupuncture $[22,23]$ were preferred in Korea.

\section{Randomized Clinical Trials (RCTs)}

The effectiveness of acupuncture in PD has been tested in many controlled clinical trials but few 
systematic reviews of these studies are available. Most of the published RCTs assessed the effect of acupuncture as monotherapy or as adjunctive therapy to conventional drugs and suggested that acupuncture had a higher efficacy than conventional drugs or no treatment on the Webster rating scale scores, Unified Parkinson's Disease Rating Scale (UPDRS), or Motor Dysfunction Rating Scale for PD. However, there are a limited number of clinical trials using placebo acupuncture as a control intervention. When compared with nonacupoint acupuncture, both acupuncture [41, 42] and electroacupuncture [43] failed to show favorable effects on UPDRS. Metaanalysis of these data also showed no significant effect of acupuncture [44], suggesting the possibility of a placebo response to acupuncture.

To date, four systematic reviews regarding efficacy of acupuncture in PD have been published [44-47]. The common conclusion of these reviews is that evidence for efficacy of acupuncture in PD was not convincing because of the poor quality of the trials. Lam, et al. searched acupuncture studies for PD in 13 databases, and found that only 10 of 784 studies met the criteria for RCTs [45]. All 10 RCTs showed serious problems in methodology and reporting, although 9 studies claimed a statistically significant positive effect from acupuncture compared to controls. In the review by Lee, et al., 11 of the 103 studies reached a level of RCTs, and these were subsequently evaluated [44]. Seven of 11 RCTs included in the analysis were rated as being of low methodological quality. All the low-quality RCTs generated positive results compared with $33 \%$ of high quality trials. It is well known that trials with less methodological rigor are more likely to exaggerate treatment effect than rigorous studies [48, 49]. Evidence-based medicine reviews by the Movement Disorder Society also concluded there is insufficient evidence to support acupuncture as symptomatic monotherapy, adjunct therapy to levodopa, in the prevention of clinical progression and motor complications, or as treatment of motor complications [50].

Besides inadequate control of placebo effects and poor methodology, heterogeneity in acupoints and acupuncture method (type, parameter, and schedule) has limited the reliability of clinical studies on acupuncture. As in experimental studies, there was no consensus in acupoints between investigators in clinical trials. The discrepancy in acupoint locations results in difficulty in interpreting and comparing studies reported in the literature [51]. As five or more acupoints were selected at a time in most of the clinical trials [44, 47], it could not be determined which acupoint was indeed effective. Only a few acupoints were used repeatedly, while most of acupoints were used only in 1 or 2 trials [45, 47]. Moreover, the efficacy of acupoints applied in clinical trials was seldom investigated in experimental studies [47]. Acupuncture parameters such as stimulation frequency and duration, retention time, and treatment sessions were variable between trials.

\section{SCIENTIFIC EVIDENCE REGARDING EFFECTIVENESS OF AYURVEDA IN THE CLINICAL TRIALS FOR PD}

There are only four clinical trials using Ayurvedic medicines in PD and no systematic review or metaanalysis. Three were open clinical trials [52-54] and one was a pilot study with a randomized, controlled, double blind, crossover design [55]. Ayurvedic medicines other than Mucuna pruriens were seldom evaluated in clinical trials. Although open clinical trials suggested some beneficial effect of Ayurvedic treatment, there was no adequate control or placebo group [52, 53]. Thus potential placebo effects cannot be excluded. In the pilot study, patients on Mucuna pruriens had longer on-time \& higher peak levodopa concentrations, compared with an equivalent dose of L-dopa, however, no significant difference was observed in the UPDRS motor score and dyskinesia score [55]. Each of the tested drugs was administered just once and sample size of this study was small.

Although the value of observation studies cannot be ignored, controlled clinical trials provide higher levels of evidence [56] and are the gold standard for measuring the efficacy of all medical interventions, including CAM methods [57]. Unfortunately, the number of clinical trials of Ayurvedic medicines in PD is insufficient and the design, methodology and quality of clinical trials lack the rigor to reach any recommendation.

\section{SCIENTIFIC EVIDENCE REGARDING EFFECTIVENESS OF HERBAL MEDICINE FOR PD IN CLINICAL TRIALS}

To our knowledge, there are only three systematic reviews or meta-analysis analyzing RCTs for efficacy of herbal medicines in PD [58-60], although numerous clinical trials have reported beneficial effects of Chinese herbal medicine in PD. In a systematic 
review by Chung, et al., 9 RCTs were included, each testing a different herbal medicine with varying compositions [58]. Of 4 studies examining herbal medicine as monotherapy, 3 including one testing Mucuna pruriens, reported similar or superior efficacy of herbal medicine compared to conventional drugs on the Webster rating scale score, UPDRS motor score, Abnormal Involuntary Movement Scale, or Goetz scale. Herbal medicine as an adjunct therapy in 5 studies also yielded a better outcome compared to the sole use of herbal medicine or conventional drugs on Webster rating scale score or UPDRS scores. However, the sample size in individual trials was relatively small suggesting the possibility of exaggeration of the efficacy of herbal medicine. Moreover, all trials except one used unvalidated diagnostic criteria. Only one trial with cross over design had placebo control and failed to show therapeutic effect of herbal medicine on dyskinesia, overall UPDRS, and PDQ39. Seven out of nine trials were conducted in China, and of the latter, 6 had major methodological design flaws.

A meta-analysis by Wang, et al. included 19 studies, which assessed clinical efficacy of Chinese herbal medicine for PD [59]. Compared with conventional treatment, herbal medicine as an adjunctive therapy improved UPDRS I, II, III, IV, and total scores. Although the 16 herbs were used more than 3 times in the 19 trials, herbal medicine differed in composition, dosage preparation, and methods or manufacturing standards. Therefore, it is difficult to assess the effect of a particular herbal medicine. Based on the funnel plot, there exists a publication bias for UPDRS III scores in the 12 trials and for UPDRS IV scores in the 7 trials with mainly positive results, and only 4 trials had placebo control. Regarding diagnostic criteria for PD, four trials used the UK brain bank diagnostic criteria, while the others used the Chinese National Diagnosis Standard. Only 8 trials provided sufficient information for randomization, 4 for blinding, and 3 for dropout rates.

Kim, et al. reviewed 64 studies among 2432 relevant publications from 15 electronic databases to evaluate the evidence of herbal medicine for PD [60]. In these 64 studies, 59 herbal preparations were used, and of these, 5 herbal medicines were used several times. Herbal medicines were composed of 3 to 20 herbs, in all studies except two. Many studies compared combination therapy with single active drugs. Combination therapy showed an improvement in PD related outcomes and a decrease in the dose of antiparkinsonian drugs. However, the funnel plots appeared asymmetric, which might have originated from publication bias or poor methodological qualities of the included studies. Out of 64 studies, only 14 were placebo controlled. When compared with placebo, specific effects were not observed in favor of herbal medicines. Direct comparison with conventional drugs also suggested that there was no evidence of better effect for herbal medicines. When risk of bias was assessed according to the criteria of Cochrane collaboration in 6 domains including random sequence generation, allocation concealment, blinding of participants, incomplete outcome data, selective reporting and other bias, none of the studies had low risk of bias in all 6 domains.

\section{SAFETY OF CAM}

CAM-researchers often failed to mention the adverse effects that may have occurred during the clinical trials [44-47, 58-60], and information about safety and adverse drug reactions in CAM is not readily available [57]. Consequently, some people may be lead to believe that CAM is safe while western medicine is toxic. Like the conventional treatments, CAMs are not free of risk. For example, Ashwagandha can cause thyrotoxicosis [61], and Chinese herbs extracts containing Aristolochic acid have been reported to cause a rapidly progressive interstitial nephritis leading to end-stage renal disease [62]. Herbal medicine related hepatotoxicity is not uncommon [63-65]. Weight reducing herbal medicines have been reported to cause hepatitis, hepatic failure, and even death $[63,65]$. Some commonly used herbs have been associated with allergic and toxic reactions [63]. Saper, et al. reported that one-fifth of Ayurvedic medicine produced in South Asia and available in Boston South Asian grocery stores, or purchased via the internet, contained potentially harmful levels of lead, mercury, and/or arsenic [66, 67]. Indeed, since 1978, more than 80 cases of lead poisoning associated with Ayurvedic medicine use have been reported worldwide [66]. Adverse effects are not only limited to Ayurvedic or Chinese herbal medicine. Live bee acupuncture therapy, can cause acute and chronic inflammatory reactions, and the venom may act as an allergen in some patients causing a severe immunological response such as anaphylaxis [68]. Aromatherapy and homeotherapy also can cause serious adverse events such as dermatitis, pulmonary edema, seizures, allergic reaction or ingestion of toxic substances $[69,70]$. 
The risk of drug interactions also applies to CAM and can lead to serious consequences if patients do not inform physicians of the concomitant use of CAM and conventional medicines. Herbal compositions are generally complex and heterogeneous. Although the combination of several herbal medicines may provide some synergistic effects, using multiple herbs can increase the risk of side effects and unwanted herbherb or drug-herb interactions. Dasgupta suggested that herbal supplements can affect concentrations of therapeutic drugs by direct interference with the measurement methodology or indirectly by altering the pharmacokinetics of co-administered drugs [71]. The ways in which CAMs interact with conventional medicines and disease status remain unsolved.

Another negative consequence of CAM is that patients may miss the chance or optimal time to receive proven effective therapy as has occurred in several high profile cases $[72,73]$.

CAM non-medical practitioners should be able to recognize serious and acute cases by symptoms in order to refer those patients to their treating physician, while at the same time it is of paramount importance that the patients inform the latter of their use of CAMs [57]. In Korea, it is not rare for a patient with an acute stroke to visit an oriental medicine clinic. If a patient is not referred to the hospital within the window of opportunity, he or she might miss the benefit of fibrinolytic therapy, resulting in serious sequelae. Therefore education about basic medical standards should be mandatory during CAM teaching courses.

\section{COST OF CAM}

The cost of CAM is not cheap. With the increasing use of CAM worldwide, there is a tendency for the cost of CAM to rise. According to a recent report by the Korean Health Insurance Review \& Assessment Service, the amount spent on traditional Korean medical treatment continues to rise at the rate of $7.7 \%$ year [74]. At this point, we need a cost comparison of CAM versus modern PD therapy.

Kim, et al. showed that the mean cost of CAM paid by patients (out-of-pocket expense) was 102.3 US Dollars (USD) per month, whereas the cost of medical treatment for PD paid by patients averaged 72.8 USD per month [4]. Another Korean study reported that the cost for CAM was 12.4 times higher than that of standard therapy, although CAM showed only partial relief of PD symptoms in 20\% of CAM users [75]. In Singapore, the average duration of use for each
CAM was 31 months with an average cost of 43.53 USD/person/type of CAM/month [6]. In Sweden, $20 \%$ of CAM users reported spending the equivalent of $50 €$ on CAM during the previous 6 months [13].

\section{ETHICAL CONSIDERATIONS}

Reporting adverse events is important to protect patients from potential risks and to prepare safety measures [76]. Therefore, a patient's condition should be monitored appropriately during treatment with systematic documentation so that reliable data on pharmaco-epidemiology and pharmaco-vigilance for safety and adverse drug reactions can be made. Currently, CAM is not regulated as rigorously as conventional medicine in terms of standardization and quality specification, and pre-marketing research and post-marketing risk management are still in an early stage in CAM, although a modest beginning has been made $[56,64,65,77,78]$.

From an ethical point of view, all relevant information about treatment options should be given to patients. Informed consent is dependent on the patient's competence to understand treatments and their consequences, and also on the ability of the health care provider to inform the patient appropriately [79]. Although healthcare providers should know about the safety of the remedies they prescribe, there is a limitation of currently available information concerning the safety of CAM. How should consent be determined where there is insufficient information about the risks?

All patients have the right to choose the treatment, and their decision has to be respected. However, not all options that patients prefer and choose are necessarily wise. Sometimes a patient might choose a CAM therapy according to spiritual beliefs, even if there is evidence that such therapy is not beneficial [79, 80]. In such situations, patient autonomy may conflict with the ethical responsibility of the health care provider. However, when principle of beneficence and non-maleficence is considered, approval or cooperation for using an unproven therapy and merely waiting to see what happens could also be considered unethical [2]. We also should consider whether expenditure on uncertain or ineffective treatments, even if harmless, is justifiable or ethical.

Another consideration is whether integrating CAM into a health care system is ethical. In Korea, some kinds of CAMs are part of the public health care system and costs are covered by a national health insurance system. In many countries, CAM services 
are not part of the public health care system, and must be paid for by either the patients themselves or by private health insurance. Assuming that CAM does more good than harm, this situation is not equitable because the unequal distribution of CAM within the population violates the fundamental ethical principle of justice. If efficacy and safety of CAM are uncertain, the integration of CAM into a health care system may be in conflict with the principles of beneficence and non-maleficence [81].

\section{CONCLUSION}

The available evidence for efficacy of CAM is insufficient and little is known about safety, despite widespread use of CAM practices among patients with PD. With increasing access to information about CAM through the media and internet where CAMs are often promoted, patients are more likely to be exposed to unvalidated information and potential risks from unproven treatments. Therefore physicians should educate themselves about evidence-based CAM treatments and provide responsible information about CAM to patients, thus helping patients to make proper decisions regarding the use of CAM.

\section{ACKNOWLEDGMENTS}

Part of the contents were presented at the 4th Asian and Oceanian Parkinson's Disease and Movement Disorders Congress in 2014. We greatly appreciate Professors Philip Thompson and Oscar Gershanik for reviewing the manuscript and valuable comments.

\section{RELEVANT CONFLICTS OF INTEREST/FINANCIAL DISCLOSURES}

The authors have no conflict of interest to report.

\section{FUNDING SOURCES FOR STUDY}

There are no funding sources for this study.

\section{REFERENCES}

[1] Nijkrake MJ, Keus SH, Kalf JG, Sturkenboom IH, Munneke M, Kappelle AC, \& Bloem BR (2007) Allied health care interventions and complementary therapies in Parkinson's disease. Parkinsonism Relat Disord, 13, S488-S494.

[2] Ernst E (2012) Ethics of complementary medicine. Clin Med, 12, 505-512.

[3] Chung SJ, Koh SB, Ju YS, \& Kim JW (2014) Nationwide survey of patient knowledge and attitudes towards human experimentation using stem cells or bee venom acupuncture for Parkinson's disease. J Mov Disord, 7, 84-91.

[4] Kim YS, Chung DI, Choi H, Baek W, Kim HY, Heo SH, Chang DI, Na HR, Kim SH, \& Koh SH (2013) Fantasies about stem cell therapy in chronic ischemic stroke patients. Stem Cells Dev, 22, 31-36.

[5] Rajendran PR, Thompson RE, \& Reich SG (2001) The use of alternative therapies by patients with Parkinson's disease. Neurology, 57, 790-794.

[6] Tan LC, Lau PN, Jamora RD, \& Chan ES (2006) Use of complementary therapies in patients with Parkinson's disease in Singapore. Mov Disord, 21, 86-89.

[7] Pecci C, Rivas MJ, Moretti C, Raina G, Ramirez CZ, Díaz S, Uribe Roca C, \& Micheli FE (2010) Use of complementary and alternative therapies in outpatients with Parkinson's disease in Argentina. Mov Disord, 25, 2094-2098.

[8] Kim SR, Lee TY, Kim MS, Lee MC, \& Chung SJ (2009) Use of complementary and alternative medicine by Korean patients with Parkinson's disease. Clin Neurol Neurosurg, 111, 156-160.

[9] Kim JY, \& Jeon BS (2012) Complementary and alternative medicine in Parkinson's disease patients in Korea. Curr Neurol Neurosci Rep, 12, 631-632.

[10] Eisenberg DM, Kessler RC, Van Rompay MI, Kaptchuk TJ, Wilkey SA, Appel S, \& Davis RB (2001) Perceptions about complementary therapies relative to conventional therapies among adults who use both: Results from a national survey. Ann Intern Med, 135, 344-351.

[11] Engel LW, \& Straus SE (2002) Development of therapeutics: Opportunities within complementary and alternative medicine. Nat Rev Drug Discov, 1, 229-237.

[12] Complementary, alternative, or integrative Health: What's in a name? https://nccih.nih.gov/health/integrative-health. Last updated March, 2015, Accessed 15 July, 2014.

[13] Lokk J, \& Nilsson M (2010) Frequency, type and factors associated with the use of complementary and alternative medicine in patients with Parkinson's disease at a neurological outpatient clinic. Parkinsonism Relat Disord, 16, 540-544.

[14] Ferry P, Johnson M, \& Wallis P (2002) Use of complementary therapies and non-prescribed medication in patients with Parkinson's disease. Postgrad Med J, 78, 612-614.

[15] Wang Y, Xie CL, Wang WW, Lu L, Fu DL, Wang XT, \& Zheng GQ (2013) Epidemiology of complementary and alternative medicine use in patients with Parkinson's disease. J Clin Neurosci, 20, 1062-1067.

[16] Kim ST, Moon W, Chae Y, Kim YJ, Lee H, \& Park HJ (2010) The effect of electroaucpuncture for 1-methyl-4-phenyl1,2,3,6-tetrahydropyridine-induced proteomic changes in the mouse striatum. J Physiol Sci, 60, 27-34.

[17] Liang XB, Liu XY, Li FQ, Luo Y, Lu J, Zhang WM, Wang XM, \& Han JS (2002) Long-term high-frequency electro-acupuncture stimulation prevents neuronal degeneration and up-regulates BDNF mRNA in the substantia nigra and ventral tegmental area following medial forebrain bundle axotomy. Brain Res Mol Brain Res, 108, 51-59.

[18] Liu XY, Zhou HF, Pan YL, Liang XB, Niu DB, Xue B, Li FQ, He QH, Wang XH, \& Wang XM (2004) Electroacupuncture stimulation protects dopaminergic neurons from inflammation-mediated damage in medial forebrain bundle-transected rats. Exp Neurol, 189, 189-196.

[19] Rui G, Guangjian Z, Yong W, Jie F, Yanchao C, Xi J, \& Fen L (2013) High frequency electro-acupuncture enhances striatum DAT and D1 receptor expression, but decreases D2 
receptor level in 6-OHDA lesioned rats. Behav Brain Res, 237, 263-269.

[20] Choi YG, Park JH, \& Lim S (2009) Acupuncture inhibits ferric iron deposition and ferritin-heavy chain reduction in an MPTP-induced parkinsonism model. Neurosci Lett, $\mathbf{4 5 0 ,}$ 92-96.

[21] Kang JM, Park HJ, Choi YG, Choe IH, Park JH, Kim YS, \& Lim S (2007) Acupuncture inhibits microglial activation and inflammatory events in the MPTP-induced mouse model. Brain Res, 1131, 211-219.

[22] Doo AR, Kim ST, Kim SN, Moon W, Yin CS, Chae Y, Park HK, Lee H, \& Park HJ (2010) Neuroprotective effects of bee venom pharmaceutical acupuncture in acute 1-methyl4-phenyl-1,2,3,6-tetrahydropyridine-induced mouse model of Parkinson's disease. Neurol Res, 32, 88-91.

[23] Kim JI, Yang EJ, Lee MS, Kim YS, Huh Y, Cho IH, Kang S, \& Koh HK (2011) Bee venom reduces neuroinflammation in the MPTP-induced model of Parkinson's disease. Int $J$ Neurosci, 121, 209-217.

[24] Kim SN, Doo AR, Park JY, Bae H, Chae Y, Shim I, Lee H, Moon W, Lee H, \& Park HJ (2011) Acupuncture enhances the synaptic dopamine availability to improve motor function in a mouse model of Parkinson's disease. PLoS One, $\mathbf{6}$, e27566.

[25] Kim YK, Lim HH, Song YK, Lee HH, Lim S, Han SM, \& Kim CJ (2005) Effect of acupuncture on 6-hydroxydopamine-induced nigrostratal dopaminergic neuronal cell death in rats. Neurosci Lett, 384, 133-138.

[26] Park HJ, Lim S, Joo WS, Yin CS, Lee HS, Lee HJ, Seo JC, Leem K, Son YS, Kim YJ, Kim CJ, Kim YS, \& Chung JH (2003) Acupuncture prevents 6-hydroxydopamine-induced neuronal death in the nigrostriatal dopaminergic system in the rat Parkinson's disease model. Exp Neurol, 180, 93-98.

[27] Yang JL, Chen JS, Yang YF, Chen JC, Lin CH, Chang RS, Tsao PJ, Chen FP, Chern CM, Tsai TH, \& Chiu JH (2011) Neuroprotection effects of retained acupuncture in neurotoxin-induced Parkinson's disease mice. Brain Behav Immun, 25, 1452-1459.

[28] Jeon S, Kim YJ, Kim ST, Moon W, Chae Y, Kang M, Chung MY, Lee H, Hong MS, Chung JH, Joh TH, Lee H, \& Park HJ (2008) Proteomic analysis of the neuroprotective mechanisms of acupuncture treatment in a Parkinson's disease mouse model. Proteomics, 8, 4822-4832.

[29] Kim SN, Kim ST, Doo AR, Park JY, Moon W, Chae Y, Yin CS, Lee H, \& Park HJ (2011) Phosphatidylinositol 3-kinase/Akt signaling pathway mediates acupunctureinduced dopaminergic neuron protection and motor function improvement in a mouse model of Parkinson's disease. Int J Neurosci, 121, 562-569.

[30] Wang H, Pan Y, Xue B, Wang X, Zhao F, Jia J, Liang $X$, \& Wang $X$ (2011) The antioxidative effect of electroacupuncture in a mouse model of Parkinson's disease. PLoS One, 6, e19790.

[31] Jia J, Li B, Sun ZL, Yu F, Wang X, \& Wang XM (2010) Electro-acupuncture stimulation acts on the basal ganglia output pathway to ameliorate motor impairment in Parkinsonian model rats. Behav Neurosci, 124, 305-310.

[32] Jia J, Sun Z, Li B, Pan Y, Wang H, Wang X, Yu F, Liu L, Zhang L, \& Wang X (2009) Electro-acupuncture stimulation improves motor disorders in Parkinsonian rats. Behav Brain Res, 205, 214-218.

[33] Khalil WK, Assaf N, ElShebiney SA, \& Salem NA (2014) Neuroprotective effects of bee venom acupuncture therapy against rotenone-induced oxidative stress and apoptosis. Neurochem Int, 80, 79-86.
[34] Kim SN, Doo AR, Park JY, Choo HJ, Shim I, Park JJ, Chae Y, Lee B, Lee H, \& Park HJ (2014) Combined treatment with acupuncture reduces effective dose and alleviates adverse effect of L-dopa by normalizing Parkinson's diseaseinduced neurochemical imbalance. Brain Res, 1544, 33-44.

[35] Liang XB, Luo Y, Liu XY, Lu J, Li FQ, Wang Q, Wang XM, \& Han JS (2003) Electro-acupuncture improves behavior and upregulates GDNF mRNA in MFB transected rats. Neuroreport, 14, 1177-1181.

[36] Sun Z, Jia J, Gong X, Jia Y, Deng J, Wang X, \& Wang X (2012) Inhibition of glutamate and acetylcholine release in behavioral improvement induced by electroacupuncture in parkinsonian rats. Neurosci Lett, 520, 32-37.

[37] Yu YP, Ju WP, Li ZG, Wang DZ, Wang YC, \& Xie AM (2010) Acupuncture inhibits oxidative stress and rotational behavior in 6-hydroxydopamine lesioned rat. Brain Res, 1336, 58-65.

[38] Wang H, Liang X, Wang X, Luo D, Jia J, \& Wang X (2013) Electro-acupuncture stimulation improves spontaneous locomotor hyperactivity in MPTP intoxicated mice. PLoS One, 8, e64403.

[39] Wang S, Fang J, Ma J, Wang Y, Liang S, Zhou D, \& Sun G (2013) Electroacupuncture-regulated neurotrophic factor mRNA expression in the substantia nigra of Parkinson's disease rats. Neural Regen Res, 8, 540-549.

[40] Hong MS, Park HK, Yang JS, Park HJ, Kim ST, Kim SN, Park JY, Song JY, Park HK, Jo DJ, Park SW, HwanYun D, Ban JY, \& Chung JH (2010) Gene expression profile of acupuncture treatment in 1-methyl-4-phenyl-1,2,3,6tetrahydropyridine-induced Parkinson's disease model. Neurol Res, 32, 74-78.

[41] Park YC, Chang DI, Lee YH, \& Park DS (2007) The study on the effect of acupuncture treatment in patients with idiopathic Parkinson's disease. J Korean Acupunct Moxibust Soc, 24, 43-54.

[42] Jung JC, Kim KH, Park YC, Kim HB, Lee SH, Chang DI, \& Lee YH (2006) The study on the effect of acupuncture on UPDRS and heart rate variability in the patients with idiopathic Parkinson's disease. J Korean Acupunct Moxibust Soc, 23, 143-153.

[43] Cristian A, Katz M, Cutrone E, \& Walker RH (2005) Evaluation of acupuncture in the treatment of Parkinson's disease: A double-blind pilot study. Mov Disord, 20, 1185-1188.

[44] Lee MS, Shin BC, Kong JC, \& Ernst E (2008) Effectiveness of acupuncture for Parkinson's disease: A systematic review. Mov Disord, 23, 1505-1515.

[45] Lam YC, Kum WF, Durairajan SS, Lu JH, Man SC, Xu M, Zhang XF, Huang XZ, \& Li M (2008) Efficacy and safety of acupuncture for idiopathic Parkinson's disease: A systematic review. J Altern Complement Med, 14, 663-671.

[46] Lee HS, Park HL, Lee SJ, Shin BC, Choi JY, \& Lee MS (2013) Scalp acupuncture for Parkinson's disease: A systematic review of randomized controlled trials. Chin J Integr Med, 19, 297-306.

[47] Kim HJ, \& Jeon BS (2014) Is acupuncture efficacious therapy in Parkinson's disease? J Neurol Sci, 341, 1-7.

[48] Smith LA, Oldman AD, McQuay HJ, \& Moore RA (2000) Teasing apart quality and validity in systematic reviews: An example from acupuncture trials in chronic neck and back pain. Pain, 86, 119-132.

[49] Egger M, Juni P, Bartlett C, Holenstein F, \& Sterne J (2003) How important are comprehensive literature searches and the assessment of trial quality in systematic reviews? Empirical study. Health Technol Assess, 7, 1-76. 
[50] Fox SH, Katzenschlager R, Lim SY, Ravina B, Seppi K, Coelho M, Poewe W, Rascol O, Goetz CG, \& Sampaio C (2011) The Movement Disorder Society Evidence-Based Medicine Review Update: Treatments for the motor symptoms of Parkinson's disease. Mov Disord, 26(S3), S2-41.

[51] Yin CS, Jeong HS, Park HJ, Baik Y, Yoon MH, Choi CB, \& Koh HG (2008) A proposed transpositional acupoint system in a mouse and rat model. Res Vet Sci, 84, 159-165.

[52] HP-200 in Parkinson's Disease Study Group (1995) An alternative medicine treatment for Parkinson's disease: Results of a multicenter clinical trial. J Altern Complement Med, 1, 249-255.

[53] Nagashayana N, Sankarankutty P, Nampoothir MR, Mohan PK, \& Mohanakumar KP (2000) Association of L-dopa with recovery following Ayurveda medication in Parkinson's disease. J Neurol Sci, 176, 124-127.

[54] Vaidya AB, Rajagopalan TG, Mankodi NA, Antarkar DS, Tathed PS, Purohit AV, \& Wadia NH (1978) Treatment of Parkinson's disease with the cowhage plant-Mucuna pruriens Bak. Neurol India, 26, 171-176.

[55] Katzenschlager R, Evans A, Manson A, Patsalos PN, Ratnaraj N, Watt H, Timmermann L, Van der Giessen R, \& Lees AJ (2004) Mucuna pruriens in Parkinson's disease: A double blind clinical and pharmacological study. J Neurol Neurosurg Psychiatry, 75, 1672-1677.

[56] Patwardhan B (2014) Bridging Ayurveda with evidencebased scientific approaches in medicine. EMPA, $\mathbf{5}, 19$.

[57] Teichfischer P (2012) Ethical implications of the increasing use of complementary and alternative medicine. Forsch Komplementmed, 19, 311-318.

[58] Chung V, Liu L, Bian Z, Zhao Z, Leuk Fong W, Kum WF, Gao J, \& Li M (2006) Efficacy and safety of herbal medicines for idiopathic Parkinson's disease: A systematic review. Mov Disord, 21, 1709-1715.

[59] Wang Y, Xie CL, Lu L, Fu DL, \& Zheng GQ (2012) Chinese herbal medicine paratherapy for Parkinson's disease: A meta-analysis of 19 randomized controlled trials. Evid Based Complement Alternat Med, 2012, 534861

[60] Kim TH, Cho KH, Jung WS, \& Lee MS (2012) Herbal medicines for Parkinson's disease: A systematic review of randomized controlled trials. PLoS One, 7, e35695.

[61] van der Hooft CS, Hoekstra A, Winter A, de Smet PA, \& Stricker BH (2005) Thyrotoxicosis following the use of ashwagandha. Ned Tijdschr Geneeskd, 149, 2637-2638.

[62] Debelle FD, Vanherweghem JL, \& Nortier JL (2008) Aristolochic acid nephropathy: A worldwide problem. Kidney Int , 74, 158-169.

[63] Ernst E (1998) Harmless herbs? A review of the recent literature. Am J Med, 104, 170-178.

[64] Teschke R, Wolff A, Frenzel C, \& Schulze J (2014) Review article: Herbal hepatotoxicity-an update on traditional Chinese medicine preparations. Aliment Pharmacol Ther, 40, 32-50.

[65] Stournaras E, \& Tziomalos K (2015) Herbal medicinerelated hepatotoxicity. World J Hepatol, 7, 2189-2193.

[66] Saper RB, Phillips RS, Sehgal A, Khouri N, Davis RB, Paquin J, Thuppil V, \& Kales SN (2008) Lead, mercury, and arsenic in US- and Indian-manufactured ayurvedic medicines sold via the Internet. JAMA, 300, 915-923.

[67] Saper RB, Kales SN, Paquin J, Burns MJ, Eisenberg DM, Davis RB, \& Phillips RS (2004) Heavy metal content of ayurvedic herbal medicine products. JAMA, 292, 28682873.

[68] Park JS, Lee MJ, Chung KH, Ko DK, \& Chung H (2013) Live bee acupuncture (Bong-Chim) dermatitis: Dermatitis due to live bee acupuncture therapy in Korea. Int J Dermatol, 52, 1519-1524.

[69] Posadzki P, Alotaibi A, \& Ernst E (2012) Adverse effects of homeopathy: A systematic review of published case reports and case series. Int J Clin Pract, 66, 1178-1188.

[70] Posadzki P, Alotaibi A, \& Ernst E (2012) Adverse effects of aromatherapy: A systematic review of case reports and case series. Int J Risk Saf Med, 24, 147-161.

[71] Dasgupta A (2008) Herbal supplements and therapeutic drug monitoring: Focus on digoxin immunoassays and interactions with St. John's wort. Ther Drug Monit, 30, 212-217.

[72] Walton AG. Steve Jobs' Cancer Treatment Regrets. http://www.forbes.com/sites/alicegwalton/2011/10/24/stevejobs-cancer-treatment-regrets/ Posted 24 October, 2011, Accessed 27 August, 2015.

[73] Song WK. Actress Jang Jin-young dies at age 37. http:// www.koreaherald.com/view.php?ud=20090902000034 . Posted 30 March, 2010, Accessed 27 August, 2015.

[74] Koreans spend more money on traditional medicine. https:// www.hira.or.kr/eng/news/02/1334837_25619.html. Posted 4 April, 2015, Accessed 15 June, 2015.

[75] Kim JY, Kim HJ, \& Jeon BS (2013) Prevalence and characteristics of nonmotor symptoms in Korean Parkinson's disease patients and its relationship with experience of alternative therapies. J Korean Neurol Assoc, 31, 8-14.

[76] Gromek K, Drumond N, \& Simas P (2015) Pharmacovigilance of herbal medicines. Int J Risk Saf Med, 27, 55-65.

[77] Cohen PA (2012) Assessing supplement safety-the FDA's controversial proposal. N Engl J Med, 366, 389-391.

[78] Zhang L, Yan J, Liu X, Ye Z, Yang X, Meyboom R, Chan K, Shaw D, \& Duez P (2012) Pharmacovigilance practice and risk control of Traditional Chinese Medicine drugs in China: Current status and future perspective. J Ethnopharmacol, 140, 519-525.

[79] Mertz M (2007) Complementary and alternative medicine: The challenges of ethical justification. A philosophical analysis and evaluation of ethical reasons for the offer, use and promotion of complementary and alternative medicine. Med Health Care Philos, 10, 329-345.

[80] Adams KE, Cohen MH, Eisenberg D, \& Jonsen AR (2002) Ethical considerations of complementary and alternative medical therapies in conventional medical settings. Ann Intern Med, 137, 660-664.

[81] Ernst E, Cohen MH, \& Stone J (2004) Ethical problems arising in evidence based complementary and alternative medicine. J Med Ethics, 30, 156-159. 